\title{
Menstrual discomfort and its influence on daily academic activities and psychosocial relationship among undergraduate female students in Nigeria
}

\author{
A. TITILAYO ${ }^{*}$, O.M. AGUNBIADE ${ }^{2}$, O. BANJO ${ }^{1}$ and A. LAWANI ${ }^{3}$ \\ ${ }^{1}$ Department of Demography \& Social Statistics, Obafemi Awolowo University, \\ Ile Ife, Osun State, Nigeria \\ ${ }^{2}$ Department of Sociology $\mathcal{E}$ Anthropology, Obafemi Awolowo University, \\ Ile Ife, Osun State, Nigeria \\ ${ }^{3}$ Department of Education, Foundation \& Counselling, Obafemi Awolowo University, \\ Ile Ife, Osun State, Nigeria
}

\begin{abstract}
Menstrual disorder is a common health problem among females in their reproductive years. It has psychosocial effects on the sufferer and her interactions with others during such periods. In Nigeria, menstrual disorder has received little research attention especially in the public health agenda. This study combines quantitative and qualitative approaches in investigating the prevalence of dysmenorrhoea and menorrhagia and their psychosocial effects by focusing on the daily activities of female undergraduates at the Obafemi Awolowo University, Ile-Ife, Nigeria. A multi-stage sampling technique was employed to select 415 female undergraduates at the University. A snowball sampling technique was used in selecting 37 informants for the in-depth interviews. Results showed a high prevalence of dysmenorrhoea $(64 \%)$ among respondents within 3 months prior to this study. Dysmenorrhoea was significant among female students who reported dizziness, headache, depression and irritation; and those whose menstrual disorder ever called for medical attention $(P<0.05)$. Similarly, menorrhagia was less frequent $(21 \%)$ than dysmenorrhoea $(64 \%)$, but occurred more significantly with dizziness, headache and depression, and those whose menstrual disorderliness ever called for medical attention or even surgical intervention $(P<0.05)$. Menstrual disorder was experienced as an objective and subjective reality among those interviewed. Both dysmenorrhoea and menorrhagia were significant predictors of psychosocial relationship of the female students $(P<0.05)$. Those with dysmenorrhoea reported one and a half times of depression than those without. However, menorrhagia appeared as the principal factor affecting their daily school activities and relationship with colleagues. Menstrual disorders prevalence is high among young undergraduates and appropriate enlightenment and treatment should be made available to young females.
\end{abstract}

Keywords: menstrual disorder, dysmenorrhoea, menorrhagia, undergraduates, Nigeria

\section{Introduction}

Menstruation, a periodic discharge of blood from uterus occurs more or less at regular monthly intervals throughout the active reproductive life of a woman. It is a traumatic experience for some women and could at times truncate their life dreams (Harlow \& Campbell, 2000; Walraven et al., 2002). Menstrual disorder and discomfort in diverse ways affect $40-95 \%$ of menstruating women. Furthermore, studies in different cultures have associated it with one of the most common causes of regular absenteeism among young women in schools, work places, sports participation, and other public functions (Banikarim et al., 2000; Grant et al., 2000; Walraven et al. 2002; El-Gilany et al., 2005).
Dysmenorrhoea, a sharp painful menstrual cramp in the lower abdomen and menorrhagia, heavy and prolonged menstrual bleeding (Grant et al., 2000; KamatemesiMugisha et al., 2007) both of menstrual disorder and discomfort are peculiar health problems that have attracted little or no health concern. Such issues are often omitted in the public health agenda of many low and middle income countries. If any, very few attempts have been made at exploring menstrual cycle problems in sub-Saharan Africa. Currently, there is paucity of data on the effects of menstrual disorder and discomfort on health status, quality of life and social integration among young women in developing countries (Pawlowski, 2004; ElGilany et al., 2005). Many reasons have been

*Correspondence: Titilayo Ayotunde; E-mail: liasuayotunde@gmail.com 
deduced as the factors responsible for the low public attention attracted to menstrual disorder and discomfort. Some women see menstruation as a 'taboo', and subject not to be discussed publicly (Harlow \& Campbell, 2000; Walraven et al. 2002; El-Gilany et al. 2005). Some other women perceive the issue of menstruation as a personal affair and if discussed publicly could cause discomfit (Walraven et al., 2002; Hickey $\&$ Balen, 2003). Lastly, the broader reproductive health concern has made some other health problems associated with women (among which is menstrual discomfort or disorder) and their implications irrelevant to public discourse (Harlow \& Campbell, 2000; KamatemesiMugisha et al., 2007).

While majority of women in their reproductive life history ever experienced menstrual discomfort or disorderliness, approximately half of the menstruating young women go through painful menstruation regularly. Studies have shown that not less than $10 \%$ of menstruating young women are incapacitated for up to three days all because of monthly menstrual disorder (Pullon et al., 1988). Patel et al. (2006) complemented this by reporting that the burden of dysmenorrhoea is greater than any other gynaecological complaints. Though mild and moderate cases of dysmenorrhoea could be treated by reassurance and paracetamol (Davis \&Westhoff, 2001), but the effect of menstrual disorder and discomfort on a woman's life could be so severe as to confine the woman to bed (El-Gilany et al., 2005). Unfortunately, due to aforementioned reasons, some young women lack experience and knowledge of effective treatment of dysmenorrhoea and other menstrual discomforts (Hillen et al., 1999).

Aside the two categories of dysmenorrhoea identified by El-Gilany et al. (2005), Chan (1972) had earlier identified four types:primaryspasmodic, secondary spasmodic, congestive and obstructive dysmenorrhoea. To a large extent, many women with menstrual disorder often experience either headache, vomiting, backache, pelvic or leg pains and even at times with two or more of the afore mentioned together. Others are menstrual discomfort that is associated with pelvic conditions or pathology that causes pelvic pain (Ryan \& Barbieri, 1995).

Despite the reality of menstrual disorder and discomfort, understanding and addressing the problems of menstruation most especially in young women has not been given considerable priority in developing countries. In all, menstruation is an event that has sociocultural and psychological implications attached to it. Hence, this study was carried out to assess the prevalence of menstrual cycle discomfort and its influence on daily academic activities and psychosocial relationship among female undergraduate students in a Nigerian University.

\section{Materials and Methods}

\section{Study subjects and design}

The study was conducted among female undergraduates at the Obafemi Awolowo University, Ile Ife, Nigeria from March to May 2007. Obafemi Awolowo University is situated in the western part of Nigeria. The study population consisted of part two to final year female students who were residents in the female halls in the University.

The study employed qualitative (indepth interviews) and quantitative (structured questionnaire) techniques in generating relevant data. Data were collected at two levels; in the first phase quantitative data was collected through a structured questionnaire. In the second phase, qualitative data were collected to complement the quantitative data. Respondents for the survey were selected using a multistage sampling technique. Purposively, the study sample was drawn from the population of female undergraduates residing in the four female halls of residence (Akintola Ladoke, Alumni, Moremi and Mozambique). These halls were numbered 1-4 in their alphabetical order as the sample frame.

The data were fed into the Statistics Package for Social Scientists (SPSS) software using the "select random sample command" one of the SPSS commands, the software was instructed to select $75 \%$ of the list. Moremi, Ladoke Akintola and Mozambique halls were invariably selected by the command. On the second stage, 243 rooms were numbered in Moremi halls, 128 rooms were numbered in Ladoke Akintola hall and 140 rooms were numbered in Mozambique halls. All numbered (511) rooms were listed and inputted into the SPSS software as the sampling frame. Again, the command was instructed to select exact 415 rooms. From the 415 selected rooms, all the female undergraduates residing in each of the selected rooms were eligible if the student had spent at least one academic session as an 
undergraduate in the school. Each of the selected room had an average of six occupants. In each of the 415 selected rooms only one volunteer that met the inclusion criteria was selected. On the overall, 415 student volunteers participated in the study.

The mixed quantitative and qualitative method adopted in this study enabled findings to be triangulated and strengthens the results. These complementary methods also allowed us to explore the issues in a more contextual and meaningful dimension than would otherwise have been possible through a single method. However, bearing in mind the limitations in using In-depth interviews for generalizations; thus, extracts from the interviews were drawn to substantiate the quantitative findings.

\section{Data collection}

Thequestionnairewasself-administered after the volunteered student had been clearly briefed on the research objectives and her rights to decline participation at any level. In order to understand the realities of menstrual disorders among the respondents, in-depth interviews (IDIs) were held with willing female undergraduates that have experienced menstrual disorder and have used any medication within the last three months preceding the study period. The IDIs' guide was designed to investigate the issues of menstrual discomfort as its affect daily activities of the female students. Information sought included questions on whether the participants have experienced menstrual disorder(s), how this problem was perceived, perceived consequences of the disorder on their daily activities and interactions with others and steps taken towards addressing the menstrual problem. All interviews were conducted in English, audio taped and transcribed. In all, 43 female undergraduates were selected through a snow balling technique, but 37 of them participated in the interview to the end.

\section{Data analysis}

The quantitative data were analyzed using the SPSS for Windows version 13. After each qualitative data collection activity, the recorded audiotapesand field notes wereused to transcribe verbatim all the interviews. Thereafter, the audio tapes and field notes were used to verify the transcribed texts, ensuring that they were correctly transcribed to preserve the meaning of the participants' words. The transcribed texts were then analyzed according to coding defined by the parameters of the research objectives. The analytic approach used in this study was influenced by Grounded Theory techniques and procedures (Strauss \& Corbin, 1998). The data were examined for salient categories, which were given a label or code, which is not merely a description of the text, but a theoretical name suggestive of a wider phenomenon imperative in the data.

\section{Ethical consideration}

The interviewers sought verbal consent of the respondents and explained the nature and objectives of the research to the volunteers and those that were willing gave their verbal consents before the questionnaires were administered. Enough care was taken to explain to the volunteers that the result of the study has no personal implications. For this study, dysmenorrhea was defined as such pains associated with menstrual periods that it kept the woman from her normal activities (Walraven et al., 2002).

\section{Results}

A total of 400 valid responses were recorded among the respondents that participated in the survey. Majority $(63.5 \%)$ of the respondents that satisfactorily completed the questionnaires were in their early twenties (20-24 years). Less than 9\% were teenagers. Almost all the respondents $(93.3 \%)$ were single and less than $7 \%$ were married at the time of the survey. Majority of the respondents $(82.3 \%)$ were Christians and only $0.3 \%$ claimed neither Islam nor Christianity. Close to $70 \%$ of the respondents experienced their first menstruation before 15 years of age. The mean age at first menarche was $13.9 \pm 1.6$ years (Table 1). Sixty-four percent (256) of the respondents reported a sharp painful cramp in the lower abdomen during menstrual period (dysmenorroea) in the last 3 months to the survey. 
Table 1: Socio-demographic characteristics of the respondents $(N=400)$

\begin{tabular}{llll}
\hline Variable & Response & Frequency & Percent \\
\hline Age (years) & $<19$ & 35 & 8.8 \\
& $20-24$ & 254 & 63.5 \\
& $25-29$ & 102 & 25.5 \\
Marital status & $30-34$ & 9 & 2.3 \\
\multirow{3}{*}{ Religion } & Single & 373 & 93.3 \\
& Married & 27 & 6.8 \\
& Christianity & 329 & 82.3 \\
Age at first menstruation (years) & Islam & 70 & 17.5 \\
& Others & 1 & 0.3 \\
& $<15$ & 278 & 69.5 \\
& $\geq 15$ & 122 & 30.5 \\
\hline
\end{tabular}

Mean age $=23.1$ years (Standard Deviation $=2.88$ )

The age range of all the in-depth interview informants was 18-31 years (mean= 22 years). Majority of the informants showed a good understanding of menstrual disorder and discomfort but with little exaggeration on the part of some. For some informants, the fact that they are naturally bound to see blood on monthly basis was a discomfort and that it does not have to be painful before discomfort set in, as testified by one of the female student: 'I use to declare the first day as 'holiday-in- pain' for myself. Even if I go to class on the first day I will not be able to do anything tangible.

This occurrence of dysmenorrhoea was found significantly frequent among female students whose menses were associated with dizziness, headache, depression, irritation and among those who claimed that menses discomfort ever called for medical attention $(P<0.05)$. It was equally observed in the bivariate relationship of the variables that dysmenorrhoea was the principal predictor of surgical intervention among young women than other factors (Table 2). The incidence of menorrhagia (excess menstrual bleeding) was less frequent (21\%) among the respondents than dysmenorrhoea. It occurred more significantly with dizziness, and headache.

Table 2: Prevalence and effect of dysmenorrhoea among university female students

\begin{tabular}{llllll}
\hline Category & Response & Total & $\begin{array}{l}\text { Dysmenorrhoea } \\
\text { No. }\end{array}$ & \% & $\begin{array}{l}\text { Significant } \\
\text { test }\end{array}$ \\
\hline Menses associated with & Yes & 107 & 83 & 77.6 & $X^{2}=11.675$ \\
dizziness & No & 293 & 173 & 59.0 & $P<0.05$ \\
Menses associated with & Yes & 94 & 77 & 91.9 & $X^{2}=17.116$ \\
headache & No & 306 & 179 & 58.5 & $P<0.05$ \\
Menses associated with & Yes & 195 & 139 & 71.3 & $X^{2}=8.757$ \\
depression & No & 205 & 56 & 57.1 & $P<0.05$ \\
Irritation menses & Yes & 151 & 124 & 82.1 & $X^{2}=34.565$ \\
& No & 249 & 132 & 53.0 & $P<0.05$ \\
Menses ever called for medical & Yes & 95 & 75 & 78.9 & $X^{2}=12.082$ \\
attention & No & 305 & 181 & 59.3 & $P<0.05$ \\
Ever had surgical intervention & Yes & 9 & 6 & 66.7 & $X^{2}=0.028$ \\
& No & 391 & 250 & 63.9 & $P>0.05$ \\
Total & & 400 & 256 & 64.0 & \\
\hline
\end{tabular}


Menorrhagia was also significant among those whose menstrual disorderliness or discomfort ever called for medical attention or even surgical intervention $(P<0.05)$ (Table 3$)$. There was a significant positive relationship between menstrual discomfort and interference in normal school activities $(P<0.05)$. Dysmenorrhoeal and menorrhagia were significant predictors of psychosocial relationship of young women $(P<0.05)$ (Table 4).

About three quarters $(74.2 \%)$ of the respondents were ever disturbed from normal school activities. In addition about half $(48.8 \%)$ of the respondents experienced psychosocial problems during menstruation period. The IDIs findings also confirmed the presence of menorrhagia and dysmenorrhoea as earlier found among the survey respondents. Majority of the informants reported that they had at one time or the other experienced troubled menstrual period within the last three months preceding the study as described by one female student: 'I use to lose much blood during my menstrual period and I have been advised by peers to always use blood capsule or tonic every month after my period, all in the name of menstruation. I have religiously adhered to this practice for a very long time as losing too much blood could be dangerous to one's health or don't you think so?' Another student had these to add:' ... I go through it every month as if I had committed a great sin that I am being punished for; it's usually a troubled moment for me whenever I am menstruating'. Female with dysmenorrhoea were significantly twice affected in their school activities than those without abdominal pain during menses. Comparatively, female students with dysmenorrhoea reported one and a half times of depression than those without dysmenorrhoea. The collective effects of menorrhagia on school activities and female students' psychosocial relationship revealed that it was a principal factor affecting their daily school activities and relationship with peers and colleagues (Table 4).

Table 3: Prevalence and effect of menorrhagia among university female students

\begin{tabular}{llllll}
\hline Category & Response & Total & \multicolumn{2}{c}{ Dysmenorrhoea } & Significant test \\
& & & No. & $\%$ & \\
\hline Menses associated with dizziness & Yes & 107 & 43 & 40.2 & $X^{2}=32.415$ \\
& No & 293 & 41 & 14.0 & $P<0.05$ \\
Menses associated with headache & Yes & 94 & 38 & 40.4 & $X^{2}=27.949$ \\
& No & 306 & 46 & 15.0 & $P<0.05$ \\
Menses associated with depression & Yes & 195 & 54 & 27.7 & $X^{2}=10.272$ \\
& No & 205 & 30 & 14.6 & $P<0.05$ \\
Irritation menses & Yes & 151 & 33 & 21.9 & $X^{2}=0.107$ \\
Menses ever called for medical attention & No & 249 & 51 & 20.5 & $P<0.05$ \\
& Yes & 95 & 32 & 33.7 & $X^{2}=12.083$ \\
Ever had surgical intervention & No & 305 & 52 & 17.0 & $P<0.05$ \\
Total & Yes & 9 & 6 & 66.7 & $X^{2}=11.574$ \\
\hline
\end{tabular}

Table 4: Logistic regression analysis of dysmenorrhoea and menorrhoea effects on daily school activities and psychosocial relationship of respondents

\begin{tabular}{|c|c|c|c|c|}
\hline Variables & Response & $\begin{array}{l}\text { Coefficient (B) } \\
\text { ratio }\end{array}$ & $\begin{array}{l}\text { Significance } \\
\text { test }\end{array}$ & Odd \\
\hline \multicolumn{5}{|l|}{ Dysmenorrhoea effects* } \\
\hline \multirow[t]{2}{*}{ Feel depressed } & Yes & 0.367 & 1.104 & 1.444 \\
\hline & No & $\mathrm{RC}$ & & 1.000 \\
\hline \multirow{2}{*}{ Affect relationship with colleagues/ friends } & Yes & 0.695 & 1.026 & 2.004 \\
\hline & No & $\mathrm{RC}$ & & 1.000 \\
\hline \multirow[t]{2}{*}{ Affect school activities } & Yes & 0.590 & 0.030 & 1.804 \\
\hline & No & $\mathrm{RC}$ & & 1.000 \\
\hline \multicolumn{5}{|l|}{ Menorrhoea effects** } \\
\hline \multirow[t]{2}{*}{ Feel depressed } & Yes & 0.477 & 0.088 & 1.611 \\
\hline & No & $\mathrm{RC}$ & & 1.000 \\
\hline \multirow[t]{2}{*}{ Affect relationship with colleagues/ friends } & Yes & 0.367 & 0.233 & 1.443 \\
\hline & No & $\mathrm{RC}$ & & 1.000 \\
\hline \multirow[t]{2}{*}{ Affect school activities } & Yes & 1.182 & 0.000 & 3.262 \\
\hline & No & $\mathrm{RC}$ & & 1.000 \\
\hline
\end{tabular}

*-2Log likelihood=377.972; Model Chi-square $\left(\chi^{2}\right)=33.193 ; P<0.001 ;{ }^{* *}$-2Log likelihood=481.878; Model Chi-square $\left(\chi^{2}\right)$ $=22.096 ; P<0.001$ 
In the in-depth interviews, some of the informants also expressed their reality as a one with both objective and subjective dimensions. The objective phase of their menstrual disorder were narrated in terms of the increase in the flow of blood during menstrual cycle, psychological discomforts, and the financial cost of coping with extra sanitary pads in case of high flow and the fear of contracting vaginal infections as described by one female student: 'Even the extra spending on the pad every month is enough as a discomfort in my own case' Another student added: 'I cut off totally from my friends and colleagues at least for the first two days of my usual menstrual periods. I would not have been able to partake in this discussion (interview) if it were my days of menstruation'

Perceived effects on their interaction with other social actors during this period dominated the subjective dimension of their menstrual discomforts. The informants admitted specific changes in their interactions or non-interaction with others during such periods: 'Whenever I am menstruating, it is like everybody is laughing at me. I always want to stay in-door especially the first and the last day of my menstrual cycle'

Majority of the informants interviewed, expressed anxiety and discouragements with the phenomenon of menstrual disorders. Some of them depicted these traits in their subjective experiences with other social actors during their menstrual cycle. One female student had this to say: 'Sometimes I ask myself why I have so much pain during menstruation and this has made me confused about the whole thing. Could it be a result of certain physiological disorder from birth or what?' Menstrual disorders become worrisome not only due to prolonged occurrence of discomforting episodes, but after repeated failures in securing reliefs. As such, it creates a pessimistic orientation to the problem as testified by another student: 'I have tried so many pain relief drugs. I do take Felvin, Boscopan among others, but none of them seems working for my case. It seems my own is so peculiar'

Apart from the disappointments in securing relief from medications, there were some misconceptions by some of the informants on the way out. Two dominant erroneous notions that emerged included engaging in pre-marital sex and giving birth to a child on time as potential reliefs from menstrual disorders: 'I always feel scared and worried when my menstrual period is coming, if it's possible that I do not menstruate, I would have preferred that. Although some of my friends have advised that I should have sex often or give birth as this may reduce my menstrual pains" Some students were even thinking of getting away of the conditions by having a baby as the following description alludes: 'I have tried several medications both traditional and modern to stop this terrible monthly pain but they told me it would not be over until I have the first baby. It is so pressing and painful that I am giving it a thought whether to have the first baby if truly it is going to stop the problem'

\section{Discussion}

Our literature search showed scanty studies on the relationship between menstrual problem and school activities or school performance in sub-Saharan Africa. The fact that menstrual discomfort or disorder was not seen as any serious gynaecological problem could be responsible for the non-existence of such study. However, it should be noted that the burden of menstrual discomfort and disorderliness might be greater than any other gynaecological complaint as observed in this study and that of Patel et al. (2006).

Majority of the informants showed a good understanding of menstrual disorder and discomfort but with the possibility of little exaggeration on the part of some. Some informants narrated the fact that they are naturally bound to see blood on monthly basis as discomforting even before the pain sets in. A level of congruence was noticed in the survey and the IDIs findings in terms of the high prevalence and the discomforting experience of menorrhagia and dysmenorrhoea. The survey results revealed a lower prevalence rate of menorrhagia than dysmenorrhoea among respondents. The prevalence rates were similar to findings from some previous studies (Pullon et al., 1988; El-Gilany et al., 2005; Patel et al., 2006; Liasu et al., 2008). As observed by Banikarim et al. (2000), cultural background and the fact that most women see menstruation (most especially excess bleeding) as a private and irritating thing to discuss publicly (Walraven et.al, 2005) could be responsible for the vast difference between the two prevalence rates.

Menstrual disorder occurs at both objective and subjective levels. The objective dimensions appeared more concrete in the narratives of the informants. Terms such as increase in the flow of blood during menstrual cycle, majority of informants cited psychological 
discomforts, and the financial cost of coping with extra sanitary pads in case of high flow and the fear of contracting vaginal infections were cited by the majority of the informants. The most commonly associated effects of dysmenorrhoea were headache and dizziness and this was similar to findings from El-Gilany et al. (2005). As reported earlier women whose menstrual period were associated with headache and abdominal pain were significantly more likely to be disturbed from normal daily activities (Davis \& Westhoff, 2001; Liasu et al. 2008). Daily home chores, going out of the home, participation in social events or sports, concentration in class and attending school were found to be some of the likely activities that were commonly limited by dysmenorrhoea and excess menstrual bleeding (El-Gilany et al., 2005). A positive significant relationship between abdominal menstrual pain and interference in normal school activities and association within peers and colleagues was found in our study.

It was also obvious that females who suffer this health problem do seek help. Help seeking in this context revealed a pluralistic approach. Some of the informants patronized orthodox and non-orthodox healing systems as well as seek help through peers. This may not be far from socio-cultural factors. This finding is similar to findings from some studies on health seeking behaviours in Nigeria (Temin et al., 1999; Jegede, 2002; Sunmola, 2005; Sunmola et al., 2007). However, after repeated failures, it could become worrisome for the sufferers and susceptible to erroneous beliefs such as the need to engage in sexual intercourse or conceive to relieve menstrual pains. This has serious implications on the reproductive of females who imbibe such notions. Engaging in unprotected sex to secure relief from menstrual pains would expose such females to unwanted pregnancies and sexually transmitted infections, including HIV/AIDS. Although this notion might not be widely accepted by all the participants in this study due to their level of exposure and educational background, but it will not be out of place if there were participants who had acted in the past by engaging in pre-marital sex as a way of getting relief over their menstrual disorders. This is possible bearing the age at menarche of the participants and their last birthday age.

Based on the findings in this study, we conclude that there is a level of influence between menstrual discomfort and university female students' normal school activities in the study area. It is essential that appropriate enlightenment and treatment mode for menstrual related cases should be made available to females (in-school and out of school) who are in their reproductive years as this will enhance their sexual health.

Received 20 February 2009

Revised 17 September 2009

Accepted 18 September 2009

\section{References}

Banikarim, C., Chacko, M.R. \& Kelder, S.H. (2000) Prevalence and impact of dysmenorrhoeal on Hispanic female adolescents. Archives of Pediatrics and Adolescent Medicine 154, 1226-1229.

Chan, D.P. (1972) Differential diagnosis of dysmenorrhoea. Medical Journal of Australia 5, 321-322.

Davis, A.R. \& Westhoff, C.L. (2001) Primary dysmenorrheal in adolescent girls and treatment with oral contraceptive. Journal of Pediatric and Adolescent Gynecology 14, 3-8.

El-Gilany, A.H., Badawi, K. \& El-Fedawy, S. (2005) Epidemiology of dysmenorrhoea among adolescent students in Mansoura, Egypt. Eastern Mediterranean Health Journal 11, 155-163.

Grant, C., Gallier, L., Fahey, T., Pearson, N. \& Sarangi, J. (2000) Management of menorrhagia in primary care - impact on referral and hysterectomy: data from the Somerset Morbidity Project. Journal of Epidemiology and Community Health 54, 709-713.

Harlow, S.D. \& Campbell, O.M.R. (2000) Menstrual dysfunction: a missed opportunity for improving reproductive health in developing countries. Reproductive Health Matters 8, 142-147.

Hickey, M. \& Balen, A. (2003) Menstrual disorders in adolescence: investigation and management. Human Reproduction Update 9, 493-504.

Hillen, T.I., Grbavac, S.L., Johnson, P.J., Straton, J.A. \& Keogh, J.M. (1999) Primary dysmenorrheal in young western Australian women: Prevalence, impact, and knowledge of treatment. Journal of Adolescent Health 25, 40-45.

Jegede, A.S. (2002) Yoruba Cultural Construction of Health and Illness. Nordic Journal of African Studies, 11, 322-335. 
Kamatemesi-Mugisha, M., Oryem-Origa, H. \& Olwa-Odyek (2007) Medicinal plants used in some gynecological morbidity ailments in Western Uganda. African Journal of Ecology 45 (Suppl. 1), 34-40.

Liasu, A., Orji, E.O. \& Lawani, A. (2008) Menstrual disorder among young female workers and its implication on job performance (case study of Obafemi Awolowo University, Nigeria). Ife Psychologia. An International Journal of Psychology in Africa 16, 224- 238.

Patel, V., Tanksale, V., Sahasrabhojanee, M., Gupte,S.\&Nevrekar,P.(2006)Theburden and determinants of dysmenorrhoea: a population-based survey of 2262 women in Goa, India BJOG. An International Journal of Obstetrics and Gynecology 113, 453-463.

Pawlowski, B. (2004) Prevalence of menstrual pain in relation to the reproductive life history of women from the Mayan rural community. Annals of Human Biology 31, 1-8.

Pullon, S., Reinken, J. \& Sparrow, M. (1988) Prevalence of dysmenorrhoea in Wellington women. New Zealand Medical Journal 10, 101, 52-54.

Ryan, K.J. \& Barbieri, R. L. (1995) The menstrual cycle. In: El-Gilany A.H., Badawi, K., and El-Fedawy, S. (2005). Epidemiology of dysmenorrhoea among adolescent students in Mansoura, Egypt. Eastern Mediterranean Health Journal11, 155-163.

Sunmola, A.M. (2005) Evaluating the sexual behaviour, barriers to condom use and its actual use by university students in Nigeria. AIDS Care 17, 208-221.

Sunmola, A.M., Olley, B.O. \& Oso, G.E. (2007) Predictors of condom use among sexually active persons involved in compulsory national service in Ibadan, Nigeria. Health Education Research, 22, 459-472.

Strauss, A. \& Corbin, J. (1998) Basics of Qualitative Research: Techniques and Procedures for Developing Grounded Theory (2nd ed.). Thousand Oaks, CA:SAGE Publications, Inc.

Temin, M.J, Okonofua, F.E, Omoridion, F.O., Renne, E.P., Coplan, P., Kris Heggenhougen, H. \& Kuafman, J. (1999) Perceptions of sexual behavior and knowledsge about sexually transmitted diseases among adolescents in Benin City, Nigeria. International Family Planning Perspective 24, 186-190.

Walraven, G., Ekpo, G., Coleman, R., Scherf, C., Morison, L. \& Harlow, S.D. (2002) Menstrual disorders in rural Gambia. Studies in Family Planning 33, 261-268. 